\title{
STUDY OF PARENTAL BELIEFS AND PRACTICES ABOUT CHILDHOOD FEVER IN A MULTICULTURAL POPULATION OF THRACE, GREECE
}

\author{
P. Tsitsani ${ }^{1,2}$, T. Theodosiou ${ }^{2}$, T. Koukou ${ }^{1}$, N. Papadopoulou ${ }^{2}$, K. Papadopoulou ${ }^{1}$, A. Papalexandri ${ }^{1}$, K. \\ Vafeiadis $^{2}$ \\ ${ }^{1}$ Paediatric Department, General Hospital of Didimoteiho, ${ }^{2}$ Department of Nursing, Kavala Institute of \\ Technology, Didimoteiho, Greece
}

Introduction and purpose: The aims of this study are to investigate

(a) parents' attitudes towards fever in their children and

(b) the common fears related to it and

(c) possibly correlate these to socio-demographic characteristics.

Materials and methods: We interviewed 316 parents, whose children attended the paediatric emergency department, using an appropriately-structured questionnaire, between January and March 2011. Data were analysed with the statistical software SPSS v17. The statistical significance of the results was tested using Chi-square and the Fisher's exact test. The significance level of all tests was $\mathrm{p}<0.05$.

Results: Parents of lower educational level are more likely to take their febrile children to the hospital as soon as fever is detected. Illiterate and primary-school educated parents also tend to administer antipyretics at a lower temperature and take more often inappropriate measures apart from antipyretics, eg sponge the child with vinegar, recommended by their grandparents. Parents fear that fever may cause seizures (53.7\%), permanent neurological damage $(22 \%)$, heart stroke $(4,5 \%)$ and death $(3,7 \%) .14 \%$ of the parents fear that fever is the symptom of an underlying serious infection (meningitis or encephalitis). Parental fears are not directly related with parents' education and with the child's age.

Conclusions: Parents still demonstrate unrealistic approaches to fever and experience undue fears. Health personnel should organise educational programmes in order to address them effectively. 